\title{
Meaningful Learning Effectiveness Related to Nets Codes in Students with Autism Spectrum Disorder
}

\author{
Manuel Ojea Rua* \\ Department of Analysis and Psychosocial-Educational Intervention, University of Vigo, Spain
}

*Corresponding author: Manuel Ojea Rúa, Department of Analysis and PsychosocialEducational Intervention, University of Vigo, Spain.

Received Date: August 20, 2018

Published Date: August 28, 2018

\begin{abstract}
One of the characteristics of students with Autism Spectrum Disorder (ASD) is significant deficits in coding global learning. Simmons Barsalou [1] propose a cognitive structure corresponding to different subsystems configured by interconnected conceptual phases, which people with ASD are important delays in semantic processing. From Vigostkian perspective, students assimilate all the concepts that make sense and are meaningful them, so this research main aim is to investigate effectiveness of creating meaningful relationships between concepts to improve learning integrated into curriculum in people with ASD. There's few evaluation studies of this theoretical principles integration into curriculum, so this research's main aim's to investigate effectiveness of creating meaningful relationships.

A total of 12 students with ASD of first secondary education participated in this study, which were divided proportionally in three groups with three didactic models to facilitate Geography and History learning: 1 Nets Group ( $n=4), 1$ Specific Group (n= 4) and 1 Regular Group (n=4). The comparative results of the three groups performed along three measurements, found through the Between- Subjects and Within- Subjects Repeated Measures Analysis (ANOVA), exhibit that students belonging to Nets Group get better data than your peers from other two groups. Likewise, Specific Group improve above the Regular Group. Improvements found don't depend on the data of the disorder level neither cognitive- perceptive degree.
\end{abstract}

Keywords: Autism; Meaningful learning, Neural networks; Semantic Memory

\section{Introduction}

The models based on existence of the activation between nets or neural nodes cognitively interconnected it was studied by Collins \& Loftus [2] through semantic words analysis. Thus, the word presentation: "July" would activate node corresponding to another related word: "August" generating, by approximation, a comprehensive relation of the initial concept: "July", both located within category of the year months. Then, a new concept: "September" is incorporate into the comprehensive category by its association to related learned concept, corroborating meaningful learning principles [3].

Simmons Barsalou [1] propose a cognitive structure corresponding to different subsystems, which configure interconnected development of conceptual nodes in semantic memory, which explain the information is processed from stimuli entry to conceptual configuration and its corresponding category construction in individuals with Autism Spectrum Disorder (ASD). First, propose a cognitive structure corresponding to different subsystems, which configure interconnected development of conceptual nodes in semantic memory, which explain the information's processed of stimuli entry to conceptual configuration and its corresponding category construction, which facilitate stimulus perception and the analysis of conceptual units through individual study of their characteristics, attributes and physical features. Now, the analytical convergence area, constitute the second level groupings, relating to characteristics analysis grouped. This analysis requires activation of relationships between concept and its conceptual attribution with other related concepts previously learned. The zones convergence holistic make up the third level, which allow configure multiple analytical properties to try to give an overall vision or conceptual group to stimulus initially perceived. This globalization process is necessary to carry out a successful conceptual attribution.

However, people with ASD present obvious errors in information understanding and, therefore, in global processing, so it's necessary 
cognitive mediation to reconstruct global of perceived stimulus (gestalt concept). Areas of modality convergence constitute fourth level, which pick up learned characteristics of previous analytical and holistic convergence zones. The main objective is allow concept integration in its category, which is fundamental aspect to facilitate cognitive economy because memory is a limited store and besides allow the access to information through the associated nets to recover the information. In this sense, people with ASD have, however, limitations to automatically create links or relationships and allow the access to information of corresponding hierarchical conceptual categories.

The last level's formed by existence of trans-modal convergence areas, which configure multi-modal categories that facilitate interrelation between the concepts corresponding to different categories modalities. This cognitive function requires the ability to elaborate inter- categories relationships since this model emerges from the consideration of activity interactive of perceptual representations about subjects-matters. In this phase, semantic processing it develops to highest level of complexity when we use different knowledge fields, from different categories integrated to form a new concept- category.

Then, concepts must be interrelated following meaningful structure to facilitate this development model that from a Vigostkian perspective in which students capture all the concepts that make sense and are meaningful them [4]. Several research are based on previous principles, Akcay [5] Romero, Cazorla \& Buzón [6] try to demonstrate science teaching and assessing what's learned via using concepts maps and interactive digital concepts. Bijsterbosch [7], Rootman-le Grage \& Blackie [8] affirm that semantics dimension can be helpful to improve evaluations and contributes to meaningful learning.

Surely, people with ASD may benefit from the programs design that encourage of relational links developed during the learning process to increase of knowledge. Just, for this reason, there are several previous studies related to ease specific perceptualcognitive development programs for individuals with ASD [9-12].

\section{Methods}

\section{Objectives}

Despite previous research, however there is few evaluation studies of this theoretical principles integration into curriculum, so this research's main aim is to investigate effectiveness of creating meaningful relationships between concepts associated with nets to facilitate the development of learning in individuals with ASD.

\section{Design}

Research design rests on quasi- experimental method of three groups: 1 Nets Group, 1 Specific Group and 1 Regular Group, with three repeated measures assessment: Performance 1-2-3.

\section{Participants}

A total of 12 students with ASD of first secondary education participated in this study, of three diagnosis levels (Level 1-2-3 variable), according American Psychiatric Association [13], of 1213 years old and different perceptive- cognitive degree (Matrix variable), which were divided proportionally, whose distribution's observed in Table 1.

Table 1: Participants' distribution $(\mathrm{N}=12)$.

\begin{tabular}{|c|c|c|c|c|c|}
\hline \multirow{2}{*}{ Matrix Variable } & \multirow{2}{*}{$\begin{array}{c}\text { Level } \\
\text { Variable }\end{array}$} & \multicolumn{3}{|c|}{ Group Variable } & \multirow{2}{*}{ Total } \\
\cline { 3 - 6 } & Nets & Specific & Regular & \\
\hline $\begin{array}{c}\text { 0-35 (low } \\
\text { percentile) }\end{array}$ & Level 3 & 1 & 1 & 0 & 2 \\
\hline $\begin{array}{c}\text { 36-64 (medium } \\
\text { percentile) }\end{array}$ & Level 2 & 1 & 1 & 2 & 4 \\
\cline { 2 - 6 } & Level 1 & 1 & 1 & 1 & 3 \\
\hline $\begin{array}{c}\text { 65-99 (high } \\
\text { percentile) }\end{array}$ & Level 1 & 1 & 1 & 1 & 3 \\
\hline Total & & 4 & 4 & 4 & 12 \\
\hline
\end{tabular}

\section{Variables}

Therefore, study variables are the following:

a. Group variable: Nets Group, Specific Group and Regular Group.

b. Level variable: Level 1-2-3 [13].

c. Matrix variable: perceptive- cognitive percentile found through SPM Progressive Matrices [14].

d. Performance variable: (Performance 1-2-3, relating with the three evaluations measures of Geography and History subject- matter of first course compulsory secondary education (1-10).

The name, categories and content of the variables may see in Table 2.

Table 2 : Study variables.

\begin{tabular}{|c|c|c|}
\hline \multirow{4}{*}{ Nome } & Category & Variable content \\
\hline \multirow{4}{*}{ Group } & Nets Group & (a) \\
\cline { 2 - 3 } & Specific Group & (b) \\
\cline { 2 - 3 } & Regular Group & (c) \\
\hline \multirow{4}{*}{ Level } & Level 1 & Low need level \\
\cline { 2 - 3 } & Level 2 & Medium need level \\
\cline { 2 - 3 } & Level 3 & High need level \\
\hline \multirow{4}{*}{ Matrix } & Percentile: 0-34 & Low percentile. \\
\cline { 2 - 3 } & Percentile: 35-64 & Medium percentile \\
\cline { 2 - 3 } & Percentile: 65-99 & $1^{\text {st }}$ evaluation \\
\hline \multirow{5}{*}{ Performance } & Measure1 (1-low...10-high) & $2^{\text {nd }}$ evaluation \\
\cline { 2 - 3 } & Measure2 (1-low...10-high) & $3^{\text {rd }}$ evaluation \\
\cline { 2 - 3 } & Measure3 (1-low...10-high) & Hightile \\
\hline
\end{tabular}

Nets program: Nets Group was based over development of relationships between meaningful linked concepts, complemented with related links (Nets Codes) to facilitate the coding and recovery curricular information of Geography and History subject, according to following learning structure:

Concept 1: "Earth is part of solar system" (...)

$\mathrm{N}$ (Nets Code): Blue circle (it can be another meaningful symbol code for each student).

Concept 1.1: (meaningful relationship with the concept1): "The system turns around sun, which's a star of the galaxy, called Milky Way" (...) 


\section{N (Nets Code): Blue circle.}

Concept 1.2 (Meaningful relationship with the concept1.1): "It's a dynamic system in which there're four mutually influenced related elements: the atmosphere, hydrosphere, lithosphere and biosphere (...)

Recovery (from learned Nets Code): blue circle signal, related learnings overlap (...)

-The texts extension depends on specific needs and characteristics of each student-

A synthesis of Nets Group didactic process observed in Graph 1.

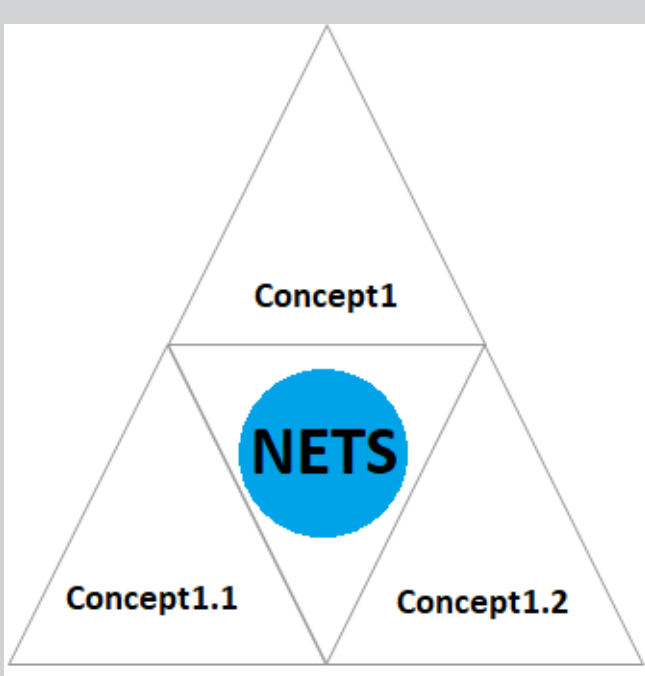

Graph 1: Nets Program synthesis.
Specific program: These didactic studiers' developed with temporal assistance from specialist teacher in support classroom (3 hours a week), in which support was carried out without use of Nets Codes.

Regular program: Studies of Regular Group were planned without specific support.

\section{Procedure}

The authorizations and ethical considerations were requested to the professionals and families of the students. Then, participants were distributed proportionally in three groups. Finally, three successive evaluation measures corresponding to the three evaluations in history and geography throughout a scholar course were carried out.

\section{Data analysis}

Results were meet through the Between- Subjects and WithinSubjects Repeated Measures Analysis (ANOVA) of statistical package SPSS version 23.

\section{Results}

\section{Comparative analysis}

Table 3 observed the multivariate test for the three successive measurements in performance variable. Results found significant changes throughout research study, concluding there're significant differences for variable: performance 1-2-3 variable along the three evaluations, indicating students have improved their grades in Geography History subject: Pillai's Trace: value $=.80, \mathrm{~F}=12.73$, Error $=6.00$, Sig $=.00$.

Table 3: Between- Groups Multivariate Tests (b).

\begin{tabular}{|c|c|c|c|c|c|c|}
\hline \multicolumn{2}{|c|}{ Effect } & Value & $\mathbf{F}$ & Hypothesis df & Error df & Sig. \\
\hline \multirow{3}{*}{ Performance } & Pillai's Trace & 0.8 & $12.73(\mathrm{a})$ & 2 & 6 & 0 \\
\hline & Wilks' Lambda & 0.19 & $12.73(\mathrm{a})$ & 2 & 6 & 0 \\
\hline & Hotelling's Trace & 4.24 & $12.73(\mathrm{a})$ & 2 & 6 & 0 \\
\hline \multirow{4}{*}{ Performance ${ }^{*}$ level } & Roy's Largest Root & 4.24 & $12.73(\mathrm{a})$ & 2 & 6 & 0 \\
\hline & Pillai's Trace & 0.45 & $2.54(\mathrm{a})$ & 2 & 6 & 0.15 \\
\hline & Wilks' Lambda & 0.54 & $2.54(\mathrm{a})$ & 2 & 6 & 0.15 \\
\hline & Hotelling's Trace & 0.85 & $2.54(\mathrm{a})$ & 2 & 6 & 0.15 \\
\hline \multirow{4}{*}{ Performance ${ }^{*}$ matrix } & Roy's Largest Root & 0.85 & $2.54(\mathrm{a})$ & 2 & 6 & 0.15 \\
\hline & Pillai's Trace & 0.26 & $1.07(\mathrm{a})$ & 2 & 6 & 0.39 \\
\hline & Wilks' Lambda & 0.73 & $1.07(\mathrm{a})$ & 2 & 6 & 0.39 \\
\hline & Hotelling's Trace & 0.35 & $1.07(\mathrm{a})$ & 2 & 6 & 0.39 \\
\hline \multirow{5}{*}{ Performance ${ }^{*}$ group } & Roy's Largest Root & 0.35 & $1.07(\mathrm{a})$ & 2 & 6 & 0.39 \\
\hline & Pillai's Trace & 1.23 & 5.61 & 4 & 14 & 0 \\
\hline & Wilks' Lambda & 0.06 & $8.73(\mathrm{a})$ & 4 & 12 & 0 \\
\hline & Hotelling's Trace & 9.76 & 12 & 4 & 10 & 0 \\
\hline & Roy's Largest Root & 9.26 & $32.44(\mathrm{~b})$ & 2 & 7 & 0 \\
\hline
\end{tabular}

a) Exact statistic.

b) The statistic is an upper bound on $\mathrm{F}$ that yields a lower bound on the significance level.

c) Design: Intercept+ Level+ Matrix+ Group.

Within Subjects Design: f Performance 
Besides, improvements found in the performance variable do not depend on the data of the level variable (Sig =15) or the variable of the matrix (Sig= 39). However, performance variable presents significant differences according to group type variable: Pillai's Trace: Value $=1.23, \mathrm{~F}=5.61$, Error $=7.00, \mathrm{Sig}=.00$.

However, comparative effects Mauchly' Between-Subjects Test (Table 4) doesn't allow refuse the equality hypothesis of means: Sig= .51 , so it's necessary to complete analysis with the WithinSubjects Effects Tests (Table 5). In the Within Subjects Design Test data of previous multivariate analysis are confirmed, in which significant critical levels are found for performance 1-2-3 variable
(Sphericity Assumed: Sig= .00, F= 9.29), as well as significant differences in relation to group type variable were found (Sphericity Assumed: Sig= .00, F= 23.44, Mean Square of Error= .114).The data summary indicated in Table 6, is estimated that the evolution of the variable performance 1-2-3 reveals significant differences throughout its evolution (Linear: $\operatorname{Sig}=.01, \mathrm{~F}=11.64$ ), also the evolution is significantly different depending on type of group of the participants (Linear: Sig= .00, F = 31.27). The Influences of level and matrix variables wasn't observed. In fact, evolution of performance variable in relation to group type variable is seen in Graph 1.

Table 4 : Mauchly's Test of Sphericity (b).

\begin{tabular}{|c|c|c|c|c|c|c|}
\hline $\begin{array}{c}\text { Within Subjects } \\
\text { Effect }\end{array}$ & Mauchly's W & $\begin{array}{c}\text { Approx. Chi- } \\
\text { Square }\end{array}$ & Df & Sig. & \multicolumn{2}{|c|}{ Epsilon(a) } \\
\hline & & & & & $\begin{array}{c}\text { Greenhouse- } \\
\text { Geisser }\end{array}$ & Huynh-Feldt \\
\hline Performance &, 80 & 1.33 & 2 & 0.51 & 0.83 & 1 \\
\hline
\end{tabular}

Table 5: Tests of Within-Subjects Effects.

\begin{tabular}{|c|c|c|c|c|c|c|}
\hline \multicolumn{2}{|c|}{ Source } & \multirow{2}{*}{$\begin{array}{c}\text { Type III Sum of Squares } \\
2.12\end{array}$} & \multirow{2}{*}{$\begin{array}{c}\text { df } \\
2\end{array}$} & \multirow{2}{*}{$\begin{array}{c}\text { Mean Square } \\
1.06\end{array}$} & \multirow{2}{*}{$\begin{array}{c}\mathbf{F} \\
9.29\end{array}$} & \multirow{2}{*}{$\begin{array}{l}\text { Sig. } \\
, 00\end{array}$} \\
\hline Performance & Sphericity Assumed & & & & & \\
\hline & Greenhouse-Geisser & 2.12 & 1.66 & 1.27 & 9.29 & ,00 \\
\hline & Huynh-Feldt & 2.12 & 2 & 1.06 & 9.29 & 00 \\
\hline & Lower-bound & 2.12 & 1 & 2.12 & 9.29 & ,01 \\
\hline \multirow[t]{4}{*}{ Performance * level } & Sphericity Assumed & 0.4 & 2 & 0.2 & 1.77 & 0.2 \\
\hline & Greenhouse-Geisser & 0.4 & 1.66 & 0.24 & 1.77 & 0.21 \\
\hline & Huynh-Feldt & 0.4 & 2 & 0.2 & 1.77 & 0.2 \\
\hline & Lower-bound & 0.4 & 1 & 0.4 & 1.77 & 0.22 \\
\hline \multirow{4}{*}{ Performance ${ }^{*}$ matrix } & Sphericity Assumed & 0.23 & 2 & 0.11 & 1.04 & 0.37 \\
\hline & Greenhouse-Geisser & 0.23 & 1.66 & 0.14 & 1.04 & 0.37 \\
\hline & Huynh-Feldt & 0.23 & 2 & 0.11 & 1.04 & 0.37 \\
\hline & Lower-bound & 0.23 & 1 & 0.23 & 1.04 & 0.34 \\
\hline \multirow{4}{*}{ Performance * group } & Sphericity Assumed & 10.69 & 4 & 2.67 & 23.44 & 0 \\
\hline & Greenhouse-Geisser & 10.69 & 3.33 & 3.2 & 23.44 & 0 \\
\hline & Huynh-Feldt & 10.69 & 4 & 2.67 & 23.44 & 0 \\
\hline & Lower-bound & 10.69 & 2 & 5.34 & 23.44 & 0 \\
\hline \multirow{4}{*}{ Error(f Performance) } & Sphericity Assumed & 1.59 & 14 & 0.11 & & \\
\hline & Greenhouse-Geisser & 1.59 & 11.67 & 0.13 & & \\
\hline & Huynh-Feldt & 1.59 & 14 & 0.11 & & \\
\hline & Lower-bound & 1.59 & 7 & 0.22 & & \\
\hline
\end{tabular}

Table 6: Tests of Within-Subjects Contrasts.

\begin{tabular}{|c|c|c|c|c|c|c|}
\hline Source & Factor1 & $\begin{array}{l}\text { Type III Sum of } \\
\text { Squares }\end{array}$ & df & Mean Square & $\mathbf{F}$ & Sig. \\
\hline \multirow{2}{*}{ Performance } & Linear & 1.56 & 1 & 1.56 & 11.64 & 0.01 \\
\hline & Quadratic & 0.55 & 1 & 0.55 & 5.94 & 0.04 \\
\hline \multirow{2}{*}{ Performance * level } & Linear & 0.02 & 1 & 0.02 & 0.16 & 0.69 \\
\hline & Quadratic & 0.38 & 1 & 0.38 & 4.06 & 0.08 \\
\hline \multirow{2}{*}{$\begin{array}{l}\text { Performance * } \\
\text { matrix }\end{array}$} & Linear & 0.01 & 1 & 0.01 & 0.1 & 0.75 \\
\hline & Quadratic & 0.22 & 1 & 0.22 & 2.37 & 0.16 \\
\hline
\end{tabular}




\begin{tabular}{|c|c|c|c|c|c|c|}
\hline \multirow{2}{*}{$\begin{array}{c}\text { F Performance* } \\
\text { group }\end{array}$} & Linear & 8.38 & 2 & 4.19 & 31.27 & 0 \\
\cline { 2 - 7 } & Quadratic & 2.3 & 2 & 1.15 & 12.28 & 0 \\
\hline $\begin{array}{c}\text { Error } \\
\text { (Performance) }\end{array}$ & Linear & 0.93 & 7 & 0.13 & & \\
\cline { 2 - 7 } & Quadratic & 0.65 & 7 & 0.09 & & \\
\hline
\end{tabular}

Graph 2 shows that differences are evident between groups, so Nets Group (blue line) found improvements above Specific Group (brown line) and finally, Regular Group get worst results (green line).

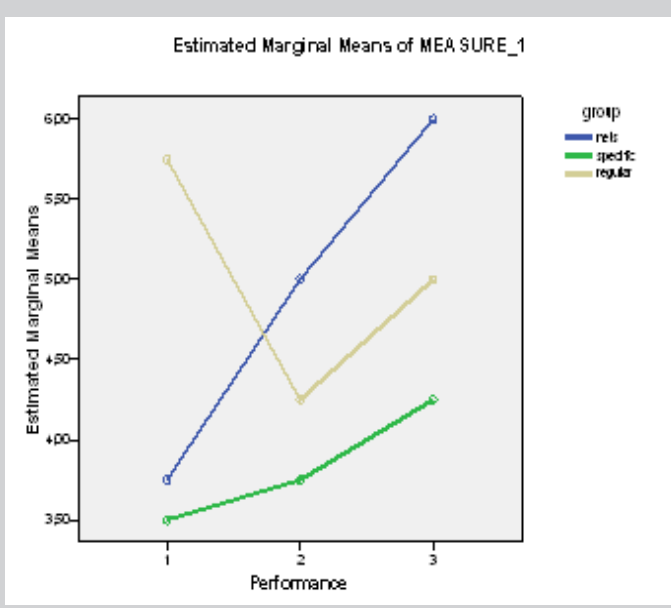

Graph 2: Profile Plots to Performance* Group type.

\section{Discussion}

Previous conclusions confirm the existence of a neural interrelation between processes learning related with nexus nets (Nets Codes) facilitates the information codification and its subsequent recovery for it's essential the learning of concepts is close in cognitive area and relate the concepts through the links (Nets) along learning process.

Successively, conceptual contents and categorical hierarchies may increase as shape meaningful memory traces and, likewise, according to specific needs of students. Likewise, when associated learning is adequate, it isn't influenced by level of disorder, nor by perceptive-cognitive capacity, although the learning evolution exhibit different temporal rhythms in the evolution process. Thus, participation effectiveness of students in the regular school and with an affective-social inclusive climate is demonstrated $[15,16]$.

However, it's necessary have support well systematized that facilitate the development of the learning of students with ASD, deepening all the factors that influence meaningful teachinglearning [17]. This systemic interaction is developed through intersection of inherent thought process, which is linked to a semantic- pragmatic process about its own functioning dynamics, through which it's understood and, finally, encoded [18-20].

In effect, neural proximity in a convergence zone reflects the similarity of phenomena characteristics that share in memory trace or content of semantic memory, which facilitates textual understanding that, according to [21], it's due to global encoded concepts semantic attribution.

\section{Conclusion}

The meaningful learning effectiveness in this research was contrasted, since students of the Nets Group have improved significantly, compared to their peers of Specific and Regular Group. Students who belong to Specific Group evolve fewer than their peers in Nets Group, but they improve better that Regular Group, which allows to conclude that temporalized support processes, according to objective curriculum are absolutely necessary to facilitate a quality education for people with ASD.

Besides, changes found between the three groups don't depend of variable: Level or diagnosis type nor on the variable: Matrix (competence level of perceptual- cognitive development), so changes in the baseline inter- groups is due to program or didactic method used. Then, the methodology based on learning from visual codes, related to the concepts helps create semantic steps in memory with meanings, as well as allows better subsequent recovery of information learned. The students' assessments who followed Nets method improved significantly more than students who belong to the Specific support Group.

Indeed students belonging to Specific Group supported through curricular adaptations, developed by specialized teachers, adjusted to their needs, but without use of keys or relational links, obtaining results in lowest Geography and History assessments than students of networks (Nets Group). Its data are better that students of Regular Group, which don't have specific support from specialist teachers, however doesn't mean that students of Regular Group don't have didactic educational reinforcement, but they have support from regular teachers in their studies. Thus, results validity's significant, since, comparing all investigated supports, Nets Group (N) was higher relational support to facilitate coding and retrieval of learned curriculum learning.

\section{Study Limitations}

This study is limited by few number of participants because working with people with specific needs is always biased by small samples, so new tests are necessary to corroborate these results.

\section{Acknowledgment}

I would like to express my gratefulness to the families and professionals of the secondary educational centers who have participated in this study.

\section{References}

1. Simmons WK, Barsalou LW (2003) The similarity in topography principle: reconciling theories of conceptual deficits. Cogn Neuropsychol 20(3): 451-486.

2. Collins AM, Loftus EF (1975) A spreading-activation theory of semantic processing. Psychological Review 82(6): 407-428.

3. Lev S Vygotsky (1962) Thought and language. Cambridge, The MIT Press, USA. 
4. Subero D, Llopart M, Siqués C, Esteban-Guitart M (2018) The mediation of teaching and learning processes through "identity artefacts." A Vygotskian perspective. Oxford Review of Education 44(2): 156-170.

5. Akcay H (2017) Constructing concept maps to encourage meaningful learning in science classroom. Education 138(1): 9-16.

6. Romero C, Cazorla M, Buzon O (2017) Meaningful learning using concept maps as a learning strategy. Journal of Technology and Science Education 7(3): 313-332.

7. Bijsterbosch E, van der Schee J, Kuiper W (2017) Meaningful learning and summative assessment in geography education: An analysis in secondary education in the Netherlands. International Research in Geographical and Environmental Education 26(1): 17-35.

8. Ilse Rootman-le Grange, Margaret AL Blackie (2018) Assessing assessment: In pursuit of meaningful learning. Chemistry education research and Practice 19(2): 484-490.

9. Cheung PP, Siu AM, Brown T, Yu M (2018) A Social-cognitive intervention program for adolescents with autism: a pilot study. Journal of Occupational Therapy, Schools \& Early Intervention 11(1): 37-48.

10. Verdier de K, Fernell E, Ek U (2018) Challenges and successfu pedagogical strategies: experiences from six Swedish students with blindness and autism in different school settings. I Autism Dev Disord 48(2): 520-532.

11. Kuder SJ, Accardo A (2018) What works for college students with autism spectrum disorder? J Autism Dev Disord 48(3): 722-731.

12. Spaniol MM, Shalev L, Kossyvaki L, Mevorach C (2018) Attention training in autism as a potential approach to improving academic performance: a school-based pilot study. J Autism Dev Disord 48(2): 592-610.
13. American Psychiatric Association (2013) Diagnostic and statistical manual of mental disorders DSM-5 ( $5^{\text {th }}$ edn) Washington, USA

14. Raven J, Raven JC, Court J H (2003 updated 2004) Manual for Raven's Progressive Matrices and Vocabulary Scales. San Antonio, TX: Harcourt Assessment.

15. Cavendish W, Connor D (2018) Toward authentic IEPs and transition plans: student, parent, and teacher perspectives. Learning Disability Quarterly 41(1): 32-43.

16. Graça Duarte Santos, Susana Sardinha, Silvia Reis (2016) Relationships in inclusive classrooms. Journal of Research in Special Educational Needs 16(1): 950-954.

17. Sanahuja-Gavaldà JM, Olmos-Rued P, Morón-Velasco M (2016) Collaborative support for inclusion. Journal of Research in Special Educational Needs 16(1): 303-307.

18. Greimel E, Nehrkorn B, Fink GR, Kukolja J, Kohls G, et al. (2012) Neural mechanisms of encoding social and no social context information in autism spectrum disorder. Neuropsychology 50(14): 3440- 3449.

19. Kimhi Y, Shoam-Kugelmas D, Agam Ben-Artzi G, Ben-Moshe I, BaumingerZviely N (2014) Theory of mind and executive function in preschoolers with typical development versus intellectually able preschoolers with autism spectrum disorder. J Autism Dev Disord 44(9): 2341-2354.

20. Voos AC, Pelphrey KA, Tirrell J, Bolling DZ, Vander Wyk B, et al. (2013). Neural mechanisms of improvements in social motivation after pivotal response treatment: two case studies. J Autism Dev Disord 43(1): 1-10.

21. Frith U (2003) Autism: explaining the enigma. ( $2^{\text {nd }}$ edn) Blackwell, Oxford, USA. 